\title{
Joint-use librariess Just how good are they?
}

\author{
By I. S. 'Bud' Call
}

\section{The delicate task of drawing boundaries and defining roles}

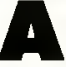

joint-use library may generally be defined as a single library facility which has been jointly created by two or more entities to serve their combined library needs. Normally, a formal operational agreement or contract defines each partner's role and responsibility in its operation, management, and financial support. It is typical for construction, equipment, and operational expenses to be equally shared. However, there are many different possibilities due to the size, nature, and number of entities involved in such a project.

Obviously, the desired outcome is that by combining the resources available from two or more agencies or institutions and sharing the operational costs, the patrons from each of the parties involved will have access to more library materials and services at less expense to each of the partners involved in the agreement.

The only significant disadvantage to a jointuse library agreement is the adjustment that each of the partners has to make in becoming sensitive to the needs of the other. Decisions and policies can no longer reflect only the needs of one or the other, but must be made in accordance with the combined needs of both. A joint-use library is totally unique unto itself and must always be treated as such.

When the BCC/South Regional Library began operations on Broward Community College's Judson D. Samuels Campus in October of 1983, it represented Florida's first effort to combine a public community college and a county library system as partners in a library. Since that time, the college has initiated two other joint-use library projects, and interest in joint-use libraries has increased throughout the country. Advancements in library technology in the form of electronic indexes and online automation systems, combined with the emphasis on shared resources have contributed significantly to this trend. Another factor which has fostered the development of these attempts at sharing resources has been the steady increase in the cost of library materials and subscriptions at a time when library budgets are being drastically reduced. All of these factors have prompted decisions to create joint-use libraries for political and economic reasons. Their potential for cost savings has made them politically popular even though, in many instances, a basic understanding of what is involved in their operation has been lacking.

\section{There is little question as to whether or not both partners get more "bang for the buck" in terms of the ... services that can be made available to their users.}

The concept of joint use is sound. There is little question as to whether or not both partners get more "bang for the buck" in terms of the library facilities and services that can be made available to their respective users. Unfortunately, many of the decisions to create joint-use libraries and the operational agreements that accompany them are being made at high levels of administration with little or no input from experienced library professionals who will ultimately be responsible for running these potential ulcer mills. The opportunity for 
excellence in terms of library services and facilities can be and often is equal to the potential for causing a great deal of frustration and dissatisfaction for the staff.

Consequently, it is the purpose of this brief article to forewarn its readers of the potential pitfalls and to point out issues that need to be studied extensively when considering the commitment to joint use. If your institution or system is considering the creation of a joint-use library and you are not being asked for input, you owe it to yourself, as a professional, to become proactive and bring these issues to the attention of your administration. Otherwise, you could find yourself dealing with some difficult circumstances later on that could have been avoided had you become actively involved in the planning process.

\section{Choose your partner and do-si-do}

Academic librarians generally have little input conceming who their joint-use library partner will be. As was stated earlier, most of these decisions are made at high administrative levels for economic or political reasons. Nevertheless, you should be aware of the fact that different partners have different needs and serve different types of patrons. For example, in combining a community college library with a university library, even though each has different needs, the difference in the nature of the combined patrons is not as great as when an academic institution merges its library with a public library. The nature of your proposed partner will directly affect the nature of the operational agreement you will have to negotiate.

\section{Administration}

Although there are many possible administrative models, there appear to be three which are most prevalent. These are as follows:

1) Co-administrators, with each representing the interests of their respective institutions, can work together as a management team responsible for the assignment of various duties, determining operating hours, work schedules, and other administrative tasks. This calls for an operational agreement that spells out areas of responsibility in great detail. In all probability, this will mean having library staff members who are employed by both of the partners and must report to their respective administrators. This can really be interesting when the two partners have different salary schedules, different work hours, and operate on different calen- dars. In addition, the academic library has to deal with issues concerning academic tenure and faculty status, issues that do not exist in public libraries. However, all of these issues can be resolved if the co-administrators are committed to making things work.

2) One administrator can be employed by one of the two partners who has, by the terms of the operational agreement, taken the responsibility for managing and operating the library. The other partner in the venture then contracts with the lead institution to provide library materials and services to its users. The obvious advantages of this model are that one person is in charge and all library personnel are reporting directly to that individual. Additionally, all personnel are working on the same salary schedule, have the same work hours, and the calendar is one that best serves the needs of both partners.

3) A governing board, consisting of representatives of the two partners, can be established as a separate entity from either of the two partners. This board hires an administrator who then reports directly to the board rather than to either of the two partners and is totally responsible for all aspects of the operation. Advantages of this model are that obviously, one partner is not likely to be favored over the other because the administrator is reporting to a bipartisan board. There are potential problems, however, with respect to determining whether the library staff will be paid by and receive benefits from one or the other of the two partners or by a separately created entity. The matter of determining the work calendar must also be addressed in this model.

Thus far, this author has been involved with three joint-use projects, all within the same institution. Two of these partnerships are between the community college and a public library system and the third is between the community college and a university. All three have, or will have, two co-administrators, with each representing their respective institution or system. As pointed out earlier, unless all responsibilities are extremely well defined in the operational agreement and unless the two individuals in charge are unusually compatible, the door to problems is being left open. At this point in time, there are probably as many models for administering these unique library operations as there are joint-use libraries. The key is to devise one that best suits the unique needs and relationships that exist in a particular situation. 


\section{Receive first class treatment at Ballen...}
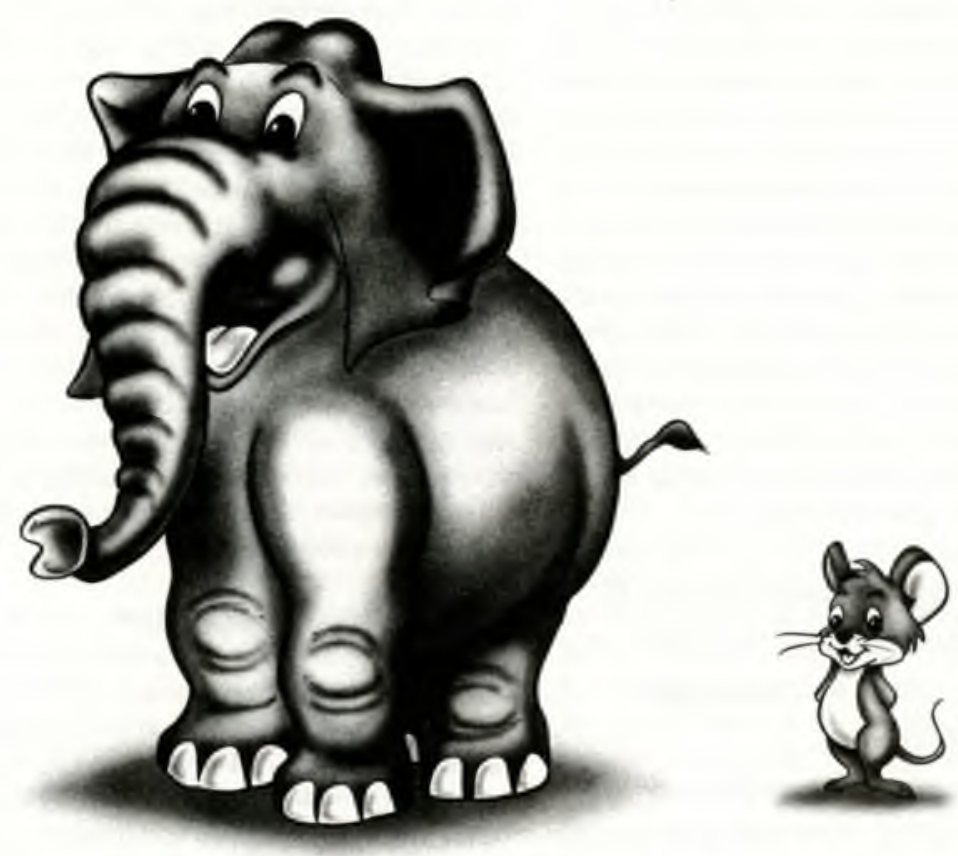

\section{no matter what your size.}

Whether your order is for a thousand books or just one, whether you are a prestigious university, medical school, or a little-known junior college, every Ballen customer receives our legendary one-to-one customized service.

That means you'll have a personal Ballen customer service representative to answer questions, report status and solve problems. You'll have a specific location in our staging area for maximum quality control. You'll have instant access to important information through BallenNet ${ }^{\mathrm{TM}}$, our interactive on-line service for order entry data and current order status. Even direct telephone access to a Ballen corporate officer, if necessary.

And despite our elephantine inventory of over 100,000 titles, with thousands of books shipped every week, our return rate squeaks in at less than $1 \%$ - the industry's lowest.

Find out how you can reap the big benefits of Ballen's personal service. Call Toll-Free (800) 645-5237 or Fax (516) 864-5850.

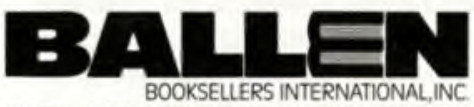

125 Ricefield Lane, Hauppauge, New York 11788 


\section{Selecting a director}

Read the classified ads section in the academic library journals or the Chronicle of Higher Education advertising for any director of libraries position, and they all have essentially the same requirements: "ALA-accredited MLS with several years of successful administrative experience in an academic library, candidate should have experience with online public access catalogs and electronic information resources, must possess effective communication and interpersonal skills, and should have experience with fiscal management." The first person who ever wrote one of these ads should be congratulated, because it was apparently so good that it is now common practice to copy that ad when the need arises to fill a similar position. In the case of selecting an administrator for a jointuse library, copying one of these descriptions to be published as your advertisement simply isn't going to be good enough.

\section{... choosing the right person is}

\section{as important a decision as there}

$$
\begin{aligned}
& \text { is when it comes to creating a } \\
& \text { joint-use library. . . . }
\end{aligned}
$$

Certainly, it is important that your director meet these kinds of criteria, but the key characteristics you should be looking for are creativity, flexibility, motivational skills, strong leadership and organizational skills, the ability to promote and sell ideas, good listening skills, and the willingness to compromise when necessary. It is of the utmost importance that the individual possess political acumen and that he or she never lose sight of the fact that a joint-use library is unique. The fact that such a library has to represent the interests of each of the partners involved dictates that it will be different from a library serving the needs of only one of the partners.

In the selection process, you must be aware that not everyone is going to be immediately interested in applying for this type of position. Generally speaking, the salaries are no higher than any other director's position for a similarsized library, and most potential applicants realize that administering a joint-use library could become a real challenge. This being the case, you may find yourself attracting candidates who loosely fall into one of two categories: 1) the candidate who is youthful, energetic, and pos- sesses the required academic credentials but lacks sufficient experience to be an effective manager in such a complicated environment, or 2) the candidate who is a seasoned veteran of library administration, possesses the necessary academic credentials, and not so many years ago possessed many of the personal characteristics one would prefer, but has not been a part of the enormous change in libraries that has only recently begun and therefore will not come to the position as a forceful motivator and an agent of change. The revolution in library technology and shared resources we have witnessed in the past five years is minor compared to the change we are about to experience. Consequently, choosing the right person is as important a decision as there is when it comes to creating a joint-use library that is going to satisfy all of its participants. Hopefully, you will be successful in attracting a director who possesses all of the necessary talents to make your project a success.

\section{Operations management}

A wide range of questions arises relative to this topic. The following are some of the major issues that must be resolved in managing a jointuse library. There will be many more items that need to be worked out in detail depending upon your particular set of circumstances.

Catalog system: If the joint-use library is brand new and the partners are starting from scratch, this poses no problem. It is more complicated if the two existing collections, both cataloged under the same system, must be merged into one. But, if the two collections to be merged are cataloged under different systems, the management opportunities that emerge are beyond your wildest dreams! Needless to say, there is no point trying to manage two separate collections under the same roof; it just isn't worth the frustration.

Automation systems: Even selecting an automation vendor to serve only the needs of your particular library or system is no simple task. In joint-use facilities, as with addressing the question of cataloging systems, this issue is not nearly as complex if the partners are starting up a brand new, stand-alone facility. However, the issue has become rather complex in two of the facilities with which this author has been involved. The college is part of a statewide College Center for Library Automation project for Florida's community college system and under normal circumstances would be 
wired directly into the state system which would give students the capability to search first their home campus, then other campuses within our district. Next, they would search the union database for all colleges in the system, and finally, each of the nine individual university databases in the state. In addition, there would be external databases mounted onto the system that would provide other benefits to the users. Further, the system would have other capabilities for staff such as a media booking component that would facilitate the scheduling and movement of media equipment and materials on and among the campuses.

However, we are partners with the public library system in two of the facilities, and in accordance with our operational agreement the two facilities are operated as regional libraries on the college campuses with special provisions being made to accommodate our students. Because books are cataloged and circulated via their automation system, there arises the question of whether to install separate terminals for our students to use for accessing the holdings of CCLA's LINCC (Library Information NetworkCommunity Colleges) database or to try and interconnect the county's system with the CCLA system so that our students can use the county's terminals to search both databases.

If the two automation systems are to be connected with each other, the following questions arise: Which is the most efficient way to do this? How much will it cost? Will our students have the full range of capabilities they would have with a direct connection to the system? On the other hand, if we install several terminals that are connected directly to LINCC, users will have more to search, but they will have to use separate terminals to search separate databases, and we will no doubt be questioned conceming the economics and politics of having duplicate terminals and systems. Further compounding this dilemma is the fact that the county library system is in the process of switching automation vendors.

I. D. cards: As simple as it may seem, this is a detail that must be worked out. Will patrons be issued separate I. D. cards by each of the partner institutions, or will there be one special card for this facility only? If so, will that card be honored at other branches or campuses of each partner? Will these borrower cards be magnetically striped for use in copy machines or printers and, if so, which partner will be responsible for accounting?
Borrowing privileges: What if the partners currently have different policies concerning who can check out materials and for how long? Will you, under the joint-use agreement, adopt the policy of one of the two partners, or will you find it necessary to devise something entirely different which will better suit your new combined circumstances?

Collection development/weeding: $\mathrm{Be}-$ cause the collection needs of the two partners will undoubtedly vary, this is an issue which should be addressed in the operational agreement. In all probability, there will be a need to set up some form of committee that will be responsible for ensuring that the needs of both participants are being met. A suitable checkand-balance system should be put in motion to monitor the weeding process as well.

Consortium memberships: Because practically every library now belongs to some type of local, state, or regional consortium, it is important that individual memberships of the two proposed partners be studied closely in order to determine whether they should attempt to become a single member of that consortium or if the unique needs of each partner might best be served through their having separate memberships. It is also possible that the partners might need to belong to different consortia. What about interlibrary loans? Suffice it to say that this is an area worthy of consideration.

\section{The facility}

When a new building is involved, the construction costs are generally shared with one of the two partners agreeing to serve as the fiscal agent responsible for bidding and contracting the construction and purchasing the furniture and equipment. But there are also many other possible combinations as well. In some cases, a facility already occupied by one of the partners may be transformed into the new library, and special arrangements must be worked out to define respective areas of responsibility. In all cases, issues concerning utilities, building maintenance, insurance, and security must all be negotiated. In the event that a new building is being constructed or an existing structure is being renovated, you can rest assured that the one aspect of the project you will be involved in is the development of the building specifications and the architectural planning process. As you enter into and work through this process, you must do so with an open mind and the commitment to be willing to compromise. 


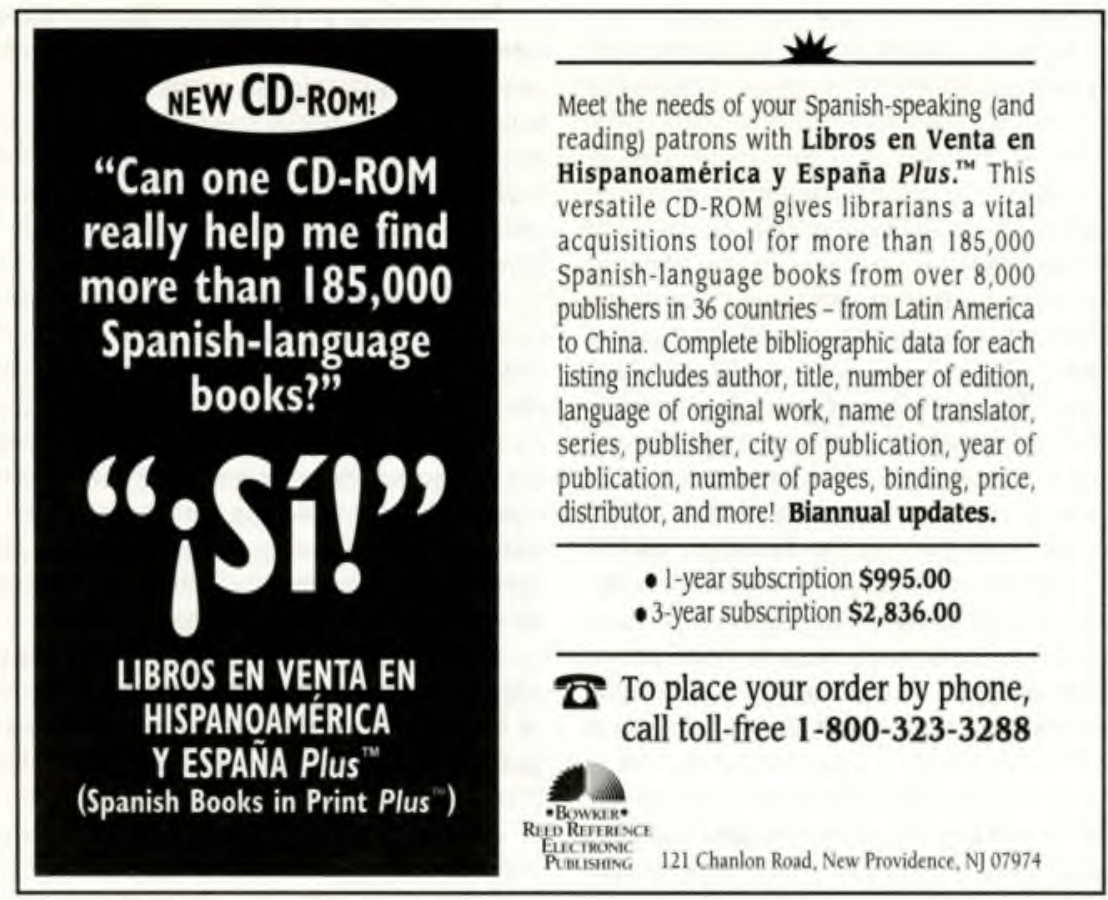

Unless you're extremely fortunate, you're not going to get everything you may want out of the deal, but it is important to let everyone know from the beginning just what it is you hope to get. With respect to the issue of compromise, it is extremely important that you take into consideration the needs of your respective patrons and put aside your own preferences so that the result is a library facility that meets the needs of both partners to the greatest extent possible. Remember, this will be a shared facility and your partner in the venture may have to serve a type of patron with whom you are completely unfamiliar. The bottom line is that although the two of you (God forbid there are more than two!) are going to live and work together in this new environment, the users should come first.

\section{Conclusion}

Up to this point we have been concerning ourselves with some of the major areas in which problems can arise. The questions and concerns that have been raised are only a few of the issues with which you will be confronted if given the opportunity to plan or work in a jointuse library. However, one must also consider the tremendous benefits that can be derived from one of these libraries. At the same time that operational costs are being drastically reduced for both partners, patrons are being provided with a larger and more diversified collection than could be made available by just one of the partners. The staff is larger and the operating hours are almost always greater. For the academic library, having a public library as a partner provides an attraction that generates exposure for the college which in turn stimulates enrollment growth. Some of their requirements such as large meeting rooms can also prove beneficial to the college.

Just how good are joint-use libraries? They're as good as we make them. They require a tremendous amount of preparation and planning, and you cannot be too careful when it comes to negotiating the operational agreement. The most important thing to remember here is that your contract or operational agreement should include the provision for annual review and/or revision. As you start to plan, visit as many sites as possible, talk with colleagues who work in them, hire a consultant, read books and articles about them, and otherwise try to gain as much information as possible. The truth is that after having done all of this, you'll still have overlooked something in the process. 